\title{
Two Aspects of Customer Participation Behaviors and the Different Effects in Service Delivery: Evidence from Home Delivery Services
}

\author{
Yuna Murae \\ University of Tsukuba \\ Bach Q. Ho \\ The University of Tokyo \\ Tatsunori Hara \\ The University of Tokyo \\ Yukihiko Okada \\ University of Tsukuba
}

This study focuses on two aspects of customer participation behaviors (CPBs) to clarify their different effects based on a customer's role as sender and receiver in home delivery services. To enhance the effect of CPBs on re-delivery as a workload of providers, we proposed actorship, which is the customers' awareness of their own roles in the service system. We then identified the factors and the effect of CPBs with two roles and actorship on re-delivery. The results indicate that a sender's CPBs reduce re-delivery through actorship. That is, the sender's experience affects the receiver's behaviors.

\section{INTRODUCTION}

The demand for consumer home delivery services has been rapidly increasing due to the expansion of consumer ecommerce (B2C-ecommerce) websites like Amazon, as well as ecommerce between individuals (C2C-ecommerce), such as in an online auction (METI, 2018; Statista, 2017). Globally, the number of parcels delivered by home delivery services has risen by about $40 \%$ since 2014, reaching 65 billion in 2016 (Statista, 2017). In addition, the convenience offered by ecommerce and home delivery services is improving. On Amazon, "Free Same-Day Delivery" is automatically provided for an order. In Japan, it is considered normal for parcels to be delivered to the consumers' home and even re-delivered the next day if the consumer is absent.

As demand increases, the workload of home delivery service providers that offer such high-cost services has become significant. In particular, re-delivery lowers labor productivity because it adds unnecessary tasks, such as re-visits, reception processing, and custody operations. This is related to the sustainability of home delivery service for providers who are short of staff. However, about $15 \%$ of the 
total parcels delivered are still re-delivered because they are free of charge. (MILT, 2017). Therefore, in order to sustain home delivery services, it is necessary to reduce re-delivery.

Because home delivery service begins when a sender dispatches a parcel, the sender's activities greatly affect service provision. However, the attempts to reduce re-delivery so far have focused primarily on the receiver. In fact, home delivery service providers have implemented specified time-zone delivery, established collection-and-distribution points and parcel lockers, and more. Yamato Transport (TA-QBIN) provides services for members whereby they can receive a message about delivery times with the help of a message application and register at-home dates in advance.

\section{FIGURE 1 HOME DELIVERY SERVICE SYSTEM}

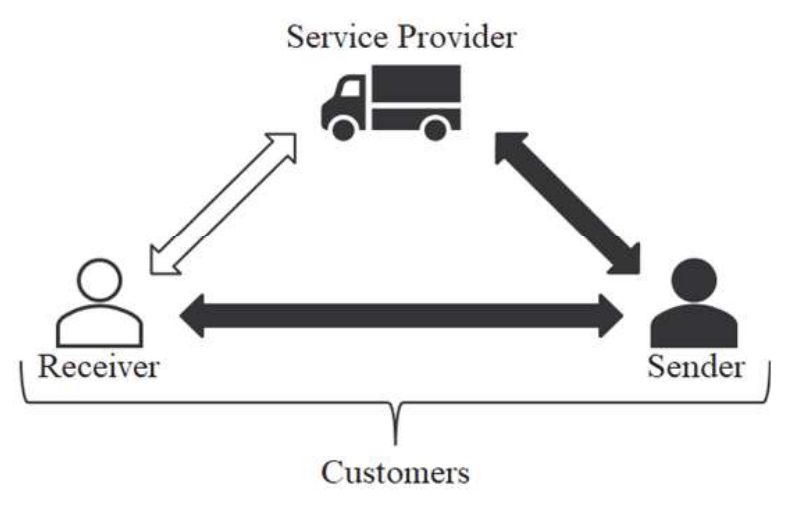

Delivery and receiving methods have been studied in previous research in order to efficiently and reliably fulfill delivery to the end customer from the final delivery point (Miyatake, Nemoto, \& Hayashi, 2016). These studies have primarily discussed home delivery service providers and receivers, that is, the existence of senders is underestimated. However, for home delivery service providers to collaborate with receivers, the information on receivers has to be provided by the senders. The present study focuses on the two roles of a customer as a sender and a receiver in home delivery services, as shown above (See Figure 1).

Customers can contribute to service providers' productivity through customer participation in service production and delivery (Lovelock \& Young, 1979). Therefore, to reduce re-delivery, it is necessary to promote customer participation behaviors (CPBs) in two roles. In addition, customers' identification of their own role toward service providers enhances CPBs and their effect (Dong, Sivakumar, Evans, \& Zou, 2015). However, in home delivery services, where customers have two roles, CPBs in each role affect service delivery process toward customers with the other role. In this study, actorship refers to customers' awareness of their own roles in the entire service system, including service providers and customers with the other role. Increasing CPBs in all roles and actorship simultaneously may reduce the workload of service providers.

The present study focuses on two aspects of CPBs because customers are both senders and receivers in home delivery services. Then, the purpose of this study to identify the factors and the effect of CPBs with two roles and actorship on re-delivery. The results indicate the difference between the effects of CPBs as a sender and as a receiver through actorship on the workload of home delivery service providers. This study gives new suggestions for customer participation research that largely considers customers as one actor and supposes a dyadic relationship between customers and service providers.

First, in Literature Review, we review the prior studies on home delivery service, customer participation, and customers' consciousness of their roles, and clarify our focus on the two aspects of CPBs. We then construct the hypotheses model on factors and effects of CPBs and actorship in Proposed Hypotheses. In Methodology, we present the survey outline, and Results presents the verification results. Finally, we discuss the verification results in Discussion and summarize this study in Conclusion. 


\section{LITERATURE REVIEW}

\section{Home Delivery Service}

To reduce the workload of home delivery service providers, many prior studies have focused on the efficiency of delivery methods and the social impact of new receiving methods. There are research studies on the efficiency of delivery methods in fields such as operations research and transportation science. Huang, Savelsbergh, and Zhao (2018) have proposed simplifying delivery by two-stage logistics in urban areas to more effectively handle the increase in parcel quantity and daily fluctuation. Miyatake et al. (2016) compared the social costs of "doorway collection-and-delivery," which delivers to the end customer only by delivery trucks and "team collection-and-delivery," which delivers using delivery trucks and trolleys. In terms of cost, "team collection-and-delivery" is superior in regions with high delivery density.

On the other hand, there are studies on the effectiveness of new receiving methods such as introducing parcel lockers and collection-and-delivery points. For example, Song, Guan, Cherrett, and Li (2013) have suggested that the delivery costs of home delivery service providers may be reduced by using collection-and-delivery points, such as supermarkets and stations, for re-delivery in the UK. In addition, the implementation of specified time-zone delivery would reduce travel distance unless the absence of the receiver does not occur (Kawanishi \& Suzuki, 2018). Deutsch and Golany (2018) have proposed a method to optimize the number and locations of parcel lockers to maximize the benefits of home delivery service providers.

These prior studies have primarily discussed home delivery service providers and receivers. In other words, in the research on home delivery service, the existence of senders is underestimated. Because home delivery service begins when a sender dispatches a parcel, the senders' activities greatly affect service provision. For home delivery service providers to collaborate with receivers, the information on receivers has to be provided by the senders; this information includes receivers' address, phone number, and at-home time. Therefore, the interaction between home delivery service providers and senders is important. Thus, the present study focuses on the two roles played by customers - that of a sender and of a receiver.

\section{Two Aspects of Customer Participation Behaviors}

Many previous studies have revealed that customer participation has a positive effect on service providers (Mustak, Jaakkola, Halinen, \& Kaartemo, 2016). In customer participation, customers supply resources such as effort, time, and information related to service production and delivery (Dabholkar, 1990; Mustak et al., 2016). Then, CPBs refer to activities of customer participation.

Lovelock and Young (1979) have suggested getting customers involved in service production and delivery, as this makes it possible to reduce the labor tasks of service providers and enhance their productivity. Since then, many studies have confirmed that an increase in CPBs contributes to an improvement in the productivity of service providers. Thus, customers were regarded as "partial employees." (Bowen, 1986; Fitzsimmons, 1985; Mills, Chase, \& Margulies, 1983). In addition, CPBs contribute not only to productivity, but also to service quality (Lengnick-Hall, 1996; Dong et al., 2015), a good relationship with service providers (Chan, Yim, \& Lam, 2010), and employee performance and commitment (Yi, Nataraajan, \& Gong, 2012).

Some research has promoted $\mathrm{CPBs}$ by identifying factors, such as service-related factors and customer-related factors (Etger, 2008). The level of CPBs required is different, depending on the nature and the context of service (Bitner, Faranda, Hubbert, \& Zeithaml, 1997; Moeller, Ciuchita, Mahr, Odekerken-Schröder, \& Fassnacht, 2013). Customers might change the level of CPBs in their role as sender or as receiver. Besides, CPBs are affected by customers' capability and psychological state (Etger, 2008; Mustak et al., 2016).

This study deals with the influence of social interest and perceived risk on CPBs. For the sustainability of home delivery service, a relationship with customers that provides mutual benefits should be established. Therefore, social interest, that is, interest in and sympathy for others (Adler, 1964; 
Crandall, 1981), is used. In addition, due to the demand increases and diversification of home delivery services, service processes have become complicated. Accordingly, customers who recognize the risk in advance - that if they cannot fulfill participation behaviors - may not take participation behaviors.

Originally, home delivery service providers only enabled the delivery of parcels for customers who wanted to send and/or receive them. In particular, to reduce re-delivery, it has been necessary for senders and receivers to provide resources such as time, labor, and information. Therefore, it is necessary to promote CPBs in two roles. However, customer participation literature so far has supposed a dyadic relationship between the firm providing a service and the customer receiving it (Dong \& Sivakumar, 2017). However, customers may play multiple roles for specific service providers, such as home delivery services (Voima, Heinonen, Strandvik, Mickelsson, \& Arantola-Hattab, 2011). For example, a customer can be a payer, a decision maker, and a user (Voima et al., 2011). In other words, customers interact with one service provider in multiple contexts. In home delivery services, the context is different between a sender and a receiver because a customer with one role is in a different situation from when he or she has the other role. Therefore, CPBs vary according to their role because their degree and nature differ with the service context (Bitner et al. 1997; Moeller et al. 2013). Since customers perform as both sender and receiver in a home delivery service, CPBs have two aspects. Thus, it is necessary to grasp CPBs for each role and to identify the effect of each on service providers.

\section{Customers' Actorship}

Customers may not be able to perform participation behaviors and/or have positive impacts (Chan et al., 2010; Dong et al., 2015; Heidenreich, Wittkowski, Handrich, \& Falk, 2015). For example, Hsieh, Yen, and Chin (2004) have found a positive relationship between customer participation and the workload of service employees. Due to customer participation, service providers' service provision depends not only on their own resources, but also on the resources of customers (Gummesson, 2008; Tax, McCutcheon, \& Wilkinson, 2013). Therefore, to reduce this workload, it is necessary to enhance customer participation and its effects through, among others, customer participation readiness (Dong et al., 2015; Larsson \& Bowen, 1989; Meuter, Bitner, Ostrom, \& Brown, 2005).

Dong et al. (2015) have claimed through experiments that customer participation readiness improves the effect of CPBs on service quality and satisfaction. It consists of role clarity, motivation, and ability (Meuter et al., 2005; Dong et al., 2015). Among these, the importance of customers' understanding of their own role is emphasized for enhancing the effect of CPBs. (Mills \& Morris, 1986; Dong et al., 2015). Role clarity is the degree to which customers understand what they should do in a service (Meuter et al., 2005). For Dong et al. (2015), the concept of role identification is about not only understanding what customers should do in a service, but also accepting it. In fact, it is necessary to recognize activities subjectively because the role is not explicitly given to customers. These studies address only the customers' behaviors toward the service providers.

However, in a home delivery service where customers play two roles, CPBs in each role affect the service delivery process toward customers in the other role. For example, if the sender specifies the delivery time at a time when the receiver is absent, the receiver cannot receive the parcel, and re-delivery occurs. Conversely, if the receiver continues to leave the absent contact form, the service toward the sender will not be fulfilled. In other words, customers have behaviors and attitudes they perform toward the service providers and the customers in the other role. They must be aware of responsibilities expected of them by service providers and customers in the other role.

In this study, customers' awareness of their role in the entire service system is called actorship. Actorship is the degree of customers' awareness of the activities they must fulfill in their own roles in the entire service system. Accordingly, increasing CPBs in all roles and actorship simultaneously may reduce the workload of service providers.

Therefore, the present study focuses on the fact that customers have two roles in home delivery services - that of a sender and of a receiver. Consequently, we aim to identify the factors and the effect on re-delivery, which is the primary workload of home delivery service providers, of CPBs in the two roles and actorship. 


\section{PROPOSED HYPOTHESES}

In this section, we propose our hypotheses on the factors and the effects of actorship and CPBs as sender and as receiver on the workload of home delivery service providers. A hypothetical model is shown below at the end of this section (See Figure 2).

First, we discuss the effects of actorship and CPBs as sender and as receiver on the workload of home delivery service providers. Actorship is the degree to which customers are aware of the activities they need to perform in their own roles in the entire service system. Ideally, customers should collaborate with other actors, including service providers, to deliver and receive services. Therefore, customers with actorship are interested in other actors in the service system and collaborate with them to ensure service. In addition, to reduce the workload of service providers, customers need to understand their own role (Mills \& Morris 1986). Therefore, customer's actorship reduces the workload of home delivery service providers $(\mathrm{H} 1)$.

\section{Hypothesis 1: Customer's actorship reduces the workload of home delivery service providers}

CPBs reduce service providers' labor tasks (Lovelock \& Young, 1979; Mills et al., 1983). On the other hand, depending on the service context, the level of CPBs required is different (Bitner et al., 1997). In other words, customers can change the degree of CPBs in their role as sender and as receiver. A sender should pack parcels and leave them with the home delivery service provider to receive service. On the other hand, a receiver can receive services only by staying at home. According to Bitner et al. (1997), a receiver only has to exist physically, but a sender has to provide some input to service providers. Therefore, a sender is required to have a higher participation level than a receiver. Therefore, CPBs as a sender has a greater influence on the service than CPBs as a receiver $(\mathrm{H} 2)$.

Hypothesis 2: Customer participation behaviors as a sender reduce the workload of home delivery service providers more than customer participation behaviors as a receiver

Next, we discuss the relationship between actorship and CPBs in two roles. Actors understand their own role and service delivery by repeating the cocreation of services (Edvardsson, Tronvoll, \& Gruber, 2011). Therefore, the more customers cocreate services by performing participation behaviors, the more customers can increase actorship. On the other hand, the higher the level of CPBs, the greater the contributions required for service delivery (Bitner et al., 1997). Therefore, the higher the level of CPBs, the more necessary it is for customers to understand their own positions and behaviors in service delivery. Therefore, CPBs as a sender promote customers' actorship more than CPBs as a receiver (H3).

Hypothesis 3: Customer participation behaviors as a sender promote customer's actorship more than customer participation behaviors as a receiver

Finally, we discuss the factors that promote CPBs. CPBs are affected not only by service context, but also by personal characteristics (Moeller et al., 2013). We use perceived risk and social interest as factors of CPBs. CPBs are activities to help others because they reduce service providers' labor tasks (Lovelock \& Young, 1979). Therefore, customers would be motivated to sympathize with service providers and help them. Social interest is a sense of interest and sympathy for others (Adler, 1964, Crandall, 1981). Activities for the sake of helping other people are motivated by empathy (Batson \& Shaw, 1991). Therefore, social interest promotes CPBs (H4). In addition, CPBs increase service quality and satisfaction (Lengnick-Hall, 1996; Dong et al., 2015), which benefits the customers. Perceived risk is potential losses incurred when a service does not perform as expect (Etgar, 2008). As perceived risk increases, the likelihood of rewards decreases (Ellen, Bearden, \& Sharma, 1991). Therefore, perceived risk reduces CPBs (H5). 
Hypothesis 4: Social interest promotes customer participation behaviors

Hypothesis 5: Perceived risk reduces customer participation behaviors

\section{FIGURE 2 PROPOSED HYPOTHESES MOEDEL}

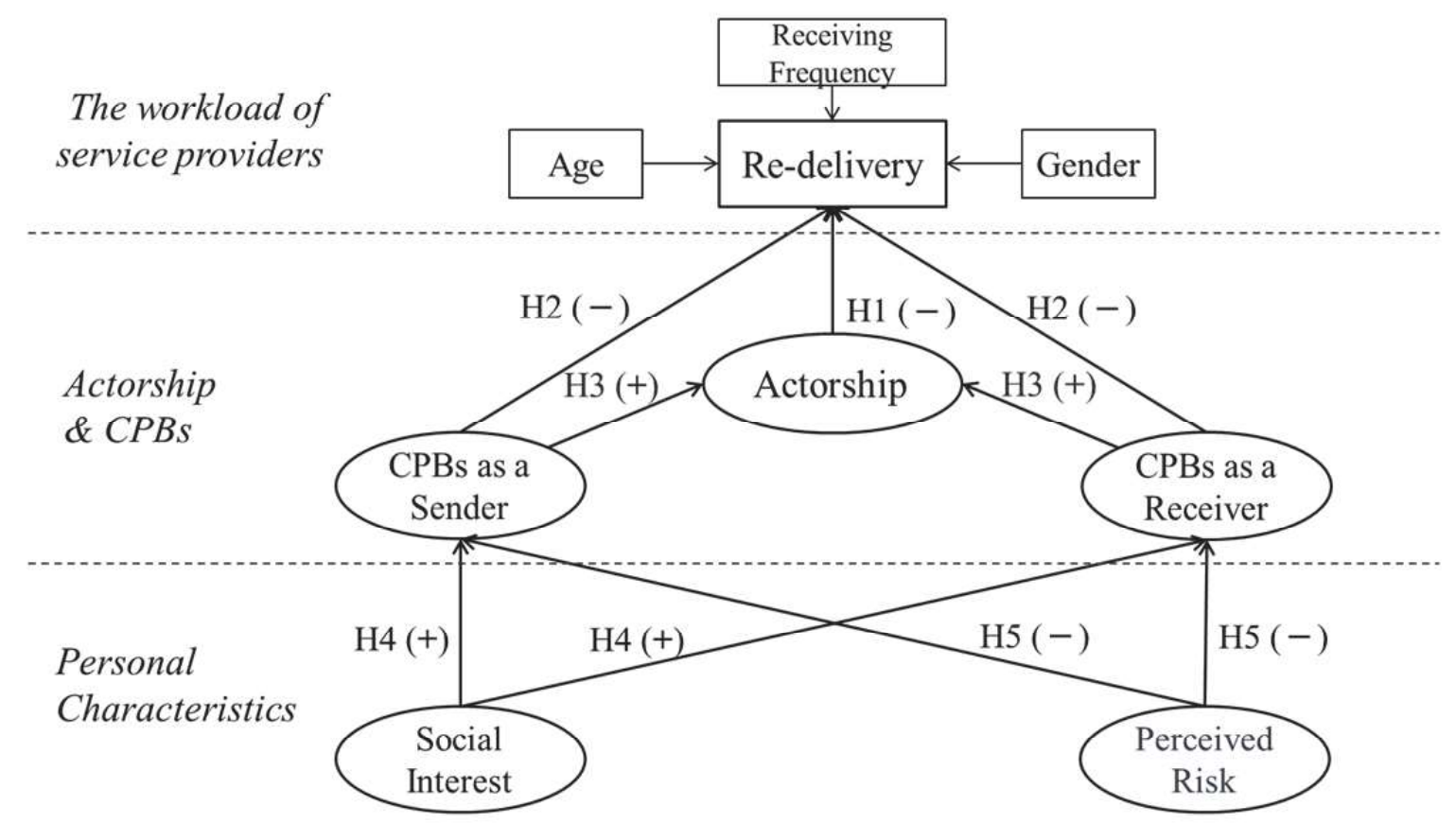

\section{METHODOLOGY}

In the present study, we collected data using an online questionnaire for general consumers and used structural equation modeling (SEM) with maximum likelihood method to verify the hypotheses. For comparison of path coefficients, the z-statistic was tested. For the analysis, IBM SPSS Statics 25 and Amos 25 Graphics were used.

\section{Sample Characteristics}

We conducted an online questionnaire survey of Japanese consumers and gathered 30,000 responses. The respondents are over 15 years old and receive parcels at least once a month. Among them, we analyzed the data of 21,102 respondents who sent parcels at least once in the last year. The average age of respondents who are subject to analysis was 48.95 years old. A total of $51.8 \%$ were females and $48.2 \%$ were males. The proportion of requests for re-delivery in the past year was 7,002 people $(33.2 \%)$ for "almost no," 8,781 people (41.6\%) for "about 20-30\%," 3,310 people (15.7\%) for "about half," 1,383 people (6.6\%) for "about $70-80 \%$ ", and 625 people (3.0\%) for "almost all."

\section{Measures}

To verify hypotheses 1 to 3, we prepared the scale of "CPBs as a receiver," $\mathrm{CPBs}$ as a receiver," "Actorship," and "the proportion of re-delivery" as a measure. CPBs was used from the value co-creation behavior scale developed by Yi and Gong (2013). Value co-creation behavior consists of CPB and customer citizenship behavior. CPBs are behaviors essential to the success of a service. Customer citizenship behaviors are not essential for the success of a service but are behaviors that add value. 
We aim to ensure customers perform activities expected of them. It allows service providers to provide service without undertaking customers' tasks. Therefore, the scale of CPB was used, which consists of four factors: information search, information sharing, responsible behavior, and personal exchange. Each factor has four items. In this research, six items with responsiveness were extracted from $\mathrm{CPB}$ and adapted to the context of a sender or a receiver.

For actorship, we used three items developed independently. Actorship is the degree to which customers are aware of activities to be performed in their own roles in the entire service system. Ideally, customers should collaborate with other actors, including service providers, to deliver and receive service. In other words, the customer collaborates with the receiver and the service provider if the customer is a sender and collaborates with the sender and the service provider if the customer is a receiver. Therefore, we used the following "agree/disagree" questions: "For better home delivery service, the activities of delivery staff and employees and my collaboration are equally important," "I collaborate with the sender to make it easier for him/her to send parcels when I am the receiver," and "I collaborate with the receiver to make it easier for him/her to receive parcels when I am the sender." CPBs and actorship were measured using a five-point Likert scale ranging from "strongly disagree" through "strongly agree."

Because re-delivery is particularly costly for home delivery service providers in Japan, it was used as the workload of home delivery service providers. Respondents were asked about the proportion of customers' requests for re-delivery in the past year in five stages: 1: "almost none"; 2 : "20-30\%"; 3 : "about half"; 4: "70-80\%"; and 5: "almost all." In addition, the following control variables were set for "the proportion of re-delivery" by considering the lifestyle in Japan: age and gender control. Gender was used as a male dummy variable. Moreover, "the proportion of re-delivery" seems to fluctuate depending on the frequency of receiving parcels in home delivery service. Consequently, the frequency of receiving parcels was used for the control variable and measured as the number of times in a month.

To verify hypotheses 4 and 5, we prepared the scale of social interest and perceived risk. The present study used social interest as developed by Kosaka (2011), which contained 24 items on the four factors of feelings of belonging to society, trust in society, feelings of contribution, and self-acceptance. In this study, 12 question items were used from the scale developed by Kosaka (2011). Each factor has three items. For perceived risk, we used three items developed independently. Respondents were asked about the complexity of the receiving and sending procedure and their distrust of service employees.

\section{RESULTS}

\section{Reliability of Variables}

Table 1 shows the average, standard deviation, and reliability coefficient of each variable. Statistics of each question item are listed in Appendix 1. We test the reliability of eight latent variables of actorship, $\mathrm{CPBs}$ as a sender, CPBs as a receiver, feelings of belonging to society, trust in society, feelings of contribution, self-acceptance, and perceived risk. Reliability is evaluated by Cronbach's $\alpha$, which is the internal consistency coefficient of each scale. Social interest (SI) consists of four latent variables, and the results of the confirmatory factor analysis are shown in Appendix 2. Moreover, to increase the reliability as much as possible, two items were deleted: "I search for information about the location of an office or official retailer where I can leave the parcel" from CPBs as a sender and CPBs as a receiver. As a result, the coefficient of reliability of each latent variable was from 0.638 to 0.856 .

Then, See Figure 3 below for the results of structural equation modeling. The fitness of the model was $\mathrm{CFI}=.797, \mathrm{PCFI}=.727, \mathrm{GFI}=.854$, AGFI $=.829$, and RMSEA $=.079$. If RMSEA is 0.1 or more, the model is unsatisfactory. Our RMSEA score confirms that our model is within the adaptable range. 
TABLE 1

STATISTICS AND COEFFICIENT OF RELIABILITY OF EACH SCALE

\begin{tabular}{|c|c|c|c|}
\hline Scales & Means & SD & Cronbach's $\alpha$ \\
\hline Actorship & 3.81 & 0.922 & 0.786 \\
\hline CPBs as a Sender & 3.75 & 0.960 & 0.855 \\
\hline CPBs as a Receiver & 3.64 & 0.980 & 0.760 \\
\hline SI (Feelings of belonging to society) & 2.82 & 1.02 & 0.841 \\
\hline SI (Trust in society) & 3.18 & 0.972 & 0.638 \\
\hline SI (Feelings of contribution) & 3.14 & 0.888 & 0.773 \\
\hline SI (Self-acceptance) & 3.20 & 1.01 & 0.724 \\
\hline Perceived Risk & 2.51 & 0.949 & 0.643 \\
\hline The Proportion of Re-delivery & 2.05 & 1.01 & - \\
\hline
\end{tabular}

FIGURE 3

RESULTS OF SEM

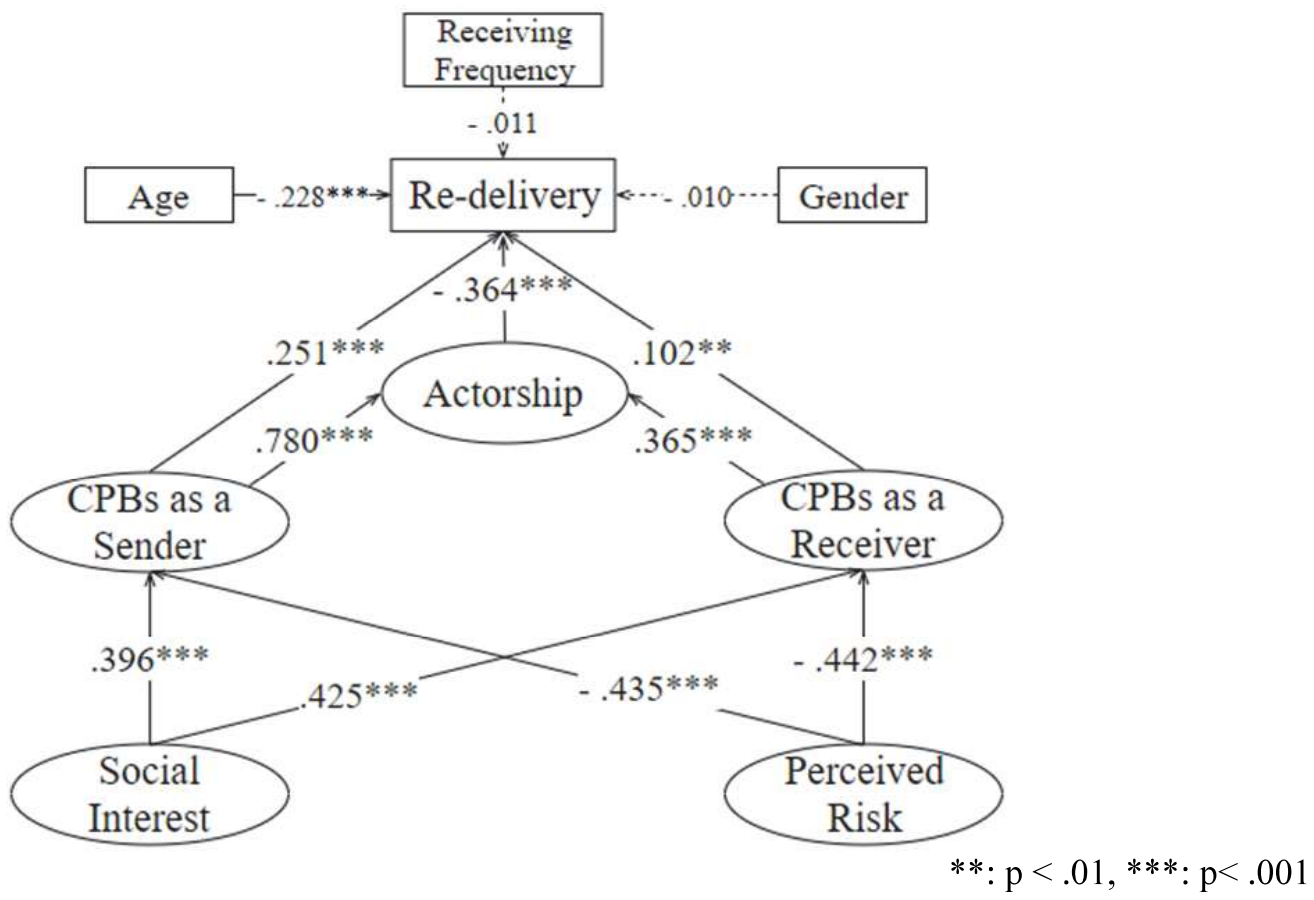

\section{Verifying the Hypotheses}

The standardizing coefficient from actorship to the proportion of re-delivery, which is the workload of home delivery service providers, was $-0.364(\mathrm{p}<0.001)$. A significant negative correlation was observed. Therefore, "H1: Customers' actorship reduces the workload of home delivery service providers" was supported.

In contrast, the standardizing coefficient from $\mathrm{CPBs}$ as a sender to the proportion of re-delivery was $0.251(\mathrm{p}<0.001)$ and the standardizing coefficient from CPBs as a receiver was $0.102(\mathrm{p}<0.01)$. A significant positive correlation was observed. That is, both CPBs as a sender and as a receiver slightly increase the proportion of re-delivery. Therefore, " $\mathrm{H} 2$ : Customer participation behaviors as a sender 
reduce the workload of home delivery service providers more than customer participation behaviors as a receiver" was not supported.

The standardizing coefficient from CPBs as a sender was $0.780(\mathrm{p}<0.001)$ to customer's actorship and the standardizing coefficient from CPBs as a receiver was $0.365(\mathrm{p}<0.001)$. A significant positive correlation relationship was recognized in both a sender and a receiver. In addition, a significant difference was confirmed $(0.1 \%$ level) between CPBs as a sender to actorship and CPBs as a receiver to actorship. Therefore, the influence on actorship from CPBs as a sender is larger in the positive direction than CPBs as a receiver. Therefore, "H3: Customer participation behaviors as a sender promote customers' actorship more than customer participation behaviors as a receiver" was supported.

The standardizing coefficient from social interest to CPBs as a sender was $0.396(\mathrm{p}<0.001)$ and to $\mathrm{CPBs}$ as a receiver was $0.425(\mathrm{p}<0.001)$. A significant positive correlation was recognized in both a sender and receiver. Therefore, "H4: Social interest promotes customer participation behaviors" was supported. Also, the standardizing coefficient from perceived risk to CPBs as a sender was -0.442 ( $p$ $<0.001$ ) and to CPBs as a receiver was -0.435 ( $\mathrm{p}<0.001$ ). A significant negative correlation was confirmed in both a sender and a receiver. Therefore, "H5: Perceived risk reduces customer participation behaviors" was supported.

\section{DISCUSSION}

The results of this study suggest that $\mathrm{CPBs}$ as a sender are important for reducing the proportion of customers' requests for re-delivery. This means that a sender's experience has strong influence on redelivery, which is the customers' behavior as receivers. Previous research on customer participation has regarded customers as single actors, with discussions being limited to their dyadic relationship with service providers (Dong \& Sivakumar, 2017). In contrast, we focused on customers as having two aspects, and identified the difference between the effects of CPBs as a sender and as a receiver through the actorship on the workload of home delivery service providers. This suggests the possibility that customers play the roles of multiple actors even if the customer partakes in the same service.

The results of the verification indicate that customers' requests for re-delivery are reduced by increasing customers' actorship, which, in turn, is promoted by enhancing CPBs. In particular, CPBs as a sender increase actorship compared with CPBs as a receiver. This is because the level of CPBs required of a sender is higher than that required of a receiver, and the necessity of understanding one's position and behaviors in service delivery is higher. However, the experiences of both CPBs increase actorship, whereas they directly increase customers' requests for re-delivery slightly.

CPBs include activities such as customers sharing information with service providers. In other words, customers who participate actively understand the service system better. Therefore, there is a possibility of performing activities that increase the workload of other actors in order to prioritize customers' own interests because they have knowledge. In fact, customers do not bother to install a parcel delivery box or receive deliveries at collection-and-delivery points, since re-delivery can be requested for free.

On the other hand, the analysis results reveal that social interest positively influences CPBs, but that $\mathrm{CPBs}$ slightly increase re-delivery. Social interest is altruistic consciousness. In other words, even customers with altruistic consciousness may prioritize their own interests, if they are familiar with the service system. If individuals continue to request re-delivery for their own benefit, home delivery service providers would be exhausted and become unable to provide services. This situation can be considered a social dilemma (Dawes, 1980). It is assumed that there are two ways to resolve the social dilemma: structural change and psychological change (Dawes, 1980; Kollock, 1998).

In structural change, measures are considered to change the structure itself of the service causing redelivery. For example, imposing a charge on re-delivery increases the consumers' benefit if they do not request re-delivery. In psychological change, we aim to change consumers' behaviors by encouraging them to follow their conscience, norms, and altruistic consciousness without changing the service structure. 
From this research, it is necessary to increase actorship that is awareness of collaboration with others. There are two measures to increase only customers' actorship without increasing CPBs. The first measure is to visualize the workload of service providers. We purpose to promote customers' empathy by helping them visualize this workload. Furthermore, the effect would be further enhanced by encouraging them to visualize the effect of their CPBs on the workload of service providers. The second measure is to deliver an educational program so that customers perform better activities by showing them the norm, such as correct packing method. Whether or not CPBs necessarily reduce the workload of service providers depends on whether some of the behaviors are convenient for the service provider or not. It is necessary to inform customers about better $\mathrm{CPBs}$ and to make it possible for customers who have performed effective CPBs to receive preferential treatment as an incentive.

\section{CONCLUSION}

As theoretical contributions, we identified the difference between the effects of CPBs due to customers' role. This lends a new perspective on prior studies that supported a dyadic relationship between service providers and customers. We focused on two aspects of CPBs because customers are both senders and receivers in home delivery services. The analysis results indicate a difference between the effects of CPBs as a sender and as a receiver through actorship on home delivery service providers. Therefore, we can claim it is necessary to consider a customer not as one actor, but to understand CPBs according to each role.

In recent service literature, the concept of "service" has moved from the dyadic relationship aforementioned to a service system with diverse actors. For example, Tax et al. (2013) have proposed a service delivery network comprising multiple providers that delivers a series of service experiences to customers. In addition, customer ecosystem (Voima et al., 2011) and customer dominant logic (Heinonen et al., 2010; Heinonen \& Strandvik, 2015) have been also proposed to extract service from customers' lives. Focusing on the customer's role, as in this research, would help us better understand customers in a service system.

Note that home delivery service providers can be subdivided into warehouse traders and truckers. Further, we can broaden the current approach by including ecommerce companies, among other entities. If these service providers are included in the service system, the customers' roles would be more than just as senders or receivers. For example, customers are also orderers who order goods; conductors who contact a home delivery company through applications; and receivers who actually receive the parcel. In future works, it will be necessary to analyze how these actors interact with each other, as well as when, where, and how customers could concretely contribute.

With the popularity and spread of mobile devices, a world in which all human beings and objects are connected is being e. Services have begun wherein consumers provide rental services as owners of goods and provide data to local governments as data collectors. Among them, the roles of customers will be more diversified. To supply sustainable service stably, it is necessary for service providers, such as firms and local governments, to control diverse customers' behaviors. For this purpose, it is desirable to understand the nature of customers based on each role, and then design services so customers can understand their responsibilities.

\section{ACKNOWLEDGEMENTS}

This study is based on results obtained from the Strategic Advancement of Multi-Purpose UltraHuman Robot and Artificial Intelligence Technologies (SamuRAI) project commissioned by the New Energy and Industrial Technology Development (NEDO). 


\section{REFERENCES}

Adler, A. (1964). Social interest: A challenge to mankind. New York, NY: Capricorn Books.

Batson, C. D., \& Shaw, L. L. (1991). Evidence for altruism: Toward a pluralism of prosocial motives. Psychological Inquiry, 2(2), 107-22.

Bitner, M.J., Faranda, W. T., Hubbert, A. R., \& Zeithaml, V. A. (1997). Customer contributions and roles in service delivery. International Journal of Service Industry Management, 8(3), 193-205.

Bowen, D. E. (1986). Managing customers as human resources in service organizations. Human Resource Management, 25(3), 371-383.

Chan, K. W., Yim, C. K., \& Lam, S. S. (2010). Is customer participation in value creation a double-edged sword? Evidence from professional financial services across cultures. Journal of Marketing, 74(3), 48-64.

Crandall, J. E. (1981). Theory and measurement of social interest: Empirical tests of Alfred Adler's concept. New York, NY: Columbia University Press.

Dabholkar, P. A. (2015). How to improve perceived service quality by increasing customer participation. In Proceedings of the 1990 Academy of Marketing Science (AMS) Annual Conference (pp. 483487). Springer, Cham.

Dawes, R. M. (1980). Social dilemmas. Annual Review of Psychology, 31(1), 169-193.

Deutsch, Y., \& Golany, B. (2018). A parcel locker network as a solution to the logistics last mile problem. International Journal of Production Research, 56(1-2), 251-261.

Dong, B., \& Sivakumar, K. (2017). Customer participation in services: Domain, scope, and boundaries. Journal of the Academy of Marketing Science, 45(6), 944-965.

Dong, B., Sivakumar, K., Evans, K. R., \& Zou, S. (2015). Effect of customer participation on service outcomes: The moderating role of participation readiness. Journal of Service Research, 18(2), 160-176.

Edvardsson, B., Tronvoll, B., \& Gruber, T. (2011). Expanding understanding of service exchange and value co-creation: A social construction approach. Journal of the Academy of Marketing Science, $39(2), 327-339$.

Ellen, P. S., Bearden, W. O., \& Sharma, S. (1991). Resistance to technological innovations: An examination of the role of self-efficacy and performance satisfaction. Journal of the Academy of Marketing Science, 19(4), 297-307.

Etgar, M. (2008). A descriptive model of the consumer co-production process. Journal of the Academy of Marketing Science, 36(1), 97-108.

Fitzsimmons, J. A. (1985). Consumer participation and productivity in service operations. Interfaces, 15(3), 60-67.

Gummesson, E. (2008). Extending the service-dominant logic: From customer centricity to balanced centricity. Journal of the Academy of Marketing Science, 36(1), 15-17.

Heidenreich, S., Wittkowski, K., Handrich, M., \& Falk, T. (2015). The dark side of customer co-creation: Exploring the consequences of failed co-created services. Journal of the Academy of Marketing Science, 43(3), 279-296.

Heinonen, K., \& Strandvik, T. (2015). Customer-dominant logic: Foundations and implications. Journal of Services Marketing, 29(6/7), 472-484.

Heinonen, K., Strandvik, T., Mickelsson, K. J., Edvardsson, B., Sundström, E., \& Andersson, P. (2010). A customer-dominant logic of service. Journal of Service Management, 21(4), 531-548.

Hsieh, A. T., Yen, C. H., \& Chin, K. C. (2004). Participative customers as partial employees and service provider workload. International Journal of Service Industry Management, 15(2), 187-199.

Huang, Y., Savelsbergh, M., \& Zhao, L. (2018). Designing logistics systems for home delivery in densely populated urban areas. Transportation Research Part B: Methodological, 115, 95-125.

Kawanishi, Y., \& Suzuki, T. (2018). Effect of the improvement in delivery method on vehicle mileage reduction in home delivery service system. Journal of the City Planning Institute of Japan, 53(1), 51-56. 
Kollock, P. (1998). Social dilemmas: The anatomy of cooperation. Annual Review of Sociology, 24(1), 183-214.

Kosaka, Y. (2011). Development of a scale of social interest. The Japanese Journal of Educational Psychology, 59(1), 88-99.

Larsson, R., \& Bowen, D. E. (1989). Organization and customer: Managing design and coordination of services. Academy of Management Review, 14(2), 213-233.

Lengnick-Hall, C. A. (1996). Customer contributions to quality: A different view of the customerorientedfirm. Academy of Management Review, 21(3), 791-824.

Lovelock, C. H., \& Young, R. F. (1979). Look to consumers to increase productivity. Harvard Business Review, 57(3), 168-178.

METI (2018, April 25). Summary of market research on e-commerce in 2017. Retrieved from http://www.meti.go.jp/policy/it_policy/statistics/outlook/h29summary.pdf

Meuter, M. L., Bitner, M. J., Ostrom, A. L., \& Brown, S. W. (2005). Choosing among alternative service delivery modes: An investigation of customer trial of self-service technologies. Journal of Marketing, 69(2), 61-83.

Mills, P. K., Chase, R. B., \& Margulies, N. (1983). Motivating the client/employee system as a service production strategy. Academy of Management Review, 8(2), 301-310.

Mills, P. K., \& Morris, J. H. (1986). Clients as "partial" employees of service organizations: Role development in client participation. Academy of Management Review, 11(4), 726-735.

MILT (2017, February). On the current situation surrounding logistics. Retrieved from http://www.mlit.go.jp/common/001173035.pdf

Miyatake, H., Nemoto, T., \& Hayashi, K. (2016). Social cost model to evaluate "team pickup/delivery" on last mile of parcel delivery network. The Japanese Journal of Transportation Economics, (59), 205-212.

Mustak, M., Jaakkola, E., Halinen, A., \& Kaartemo, V. (2016). Customer participation management: Developing a comprehensive framework and a research agenda. Journal of Service Management, 27(3), 250-275.

Moeller, S., Ciuchita, R., Mahr, D., Odekerken-Schröder, G., \& Fassnacht, M. (2013). Uncovering collaborative value creation patterns and establishing corresponding customer roles. Journal of Service Research, 16(4), 471-487.

Song, L., Guan, W., Cherrett, T., \& Li, B. (2013). Quantifying the greenhouse gas emissions of local collection-and-delivery points for last-mile deliveries. Transportation Research Record: Journal of the Transportation Research Board, 2340, 66-73.

Statista (2017). 65 billion parcels were shipped in 2016. Retrieved from https://www.statista.com/chart/10922/parcel-shipping-volume-and-parcel-spend-in-selectedcountries/

Tax, S. S., McCutcheon, D., \& Wilkinson, I. F. (2013). The service delivery network (SDN): A customercentric perspective of the customer journey. Journal of Service Research, 16(4), 454-470.

Voima, P., Heinonen, K., Strandvik, T., Mickelsson, K. J., \& Arantola-Hattab, J. (2011). A customer ecosystem perspective on service. QUIS 12: Advances in Service Quality, Innovation and Excellence, 1015-1024.

Yi, Y., \& Gong, T. (2013). Customer value co-creation behavior: Scale development and validation. Journal of Business Research, 66(9), 1279-1284.

Yi, Y., Nataraajan, R., \& Gong, T. (2012). Customer participation and citizenship behavioral influences on employee performance, satisfaction, commitment, and turnover intention. Journal of Business Research, 64(1), 87-95. 


\section{APPENDICES}

\section{Appendix 1}

TABLE A1 shows the list of questionnaire items used in this study.

\section{TABLE A1 \\ QUESTIONNAIRE ITEMS LIST}

\begin{tabular}{|c|c|c|c|c|}
\hline Scales & Questionnaire Items & Means & SD & $\begin{array}{c}\text { Standardized } \\
\text { Coefficient }\end{array}$ \\
\hline \multirow{3}{*}{ Actorship } & $\begin{array}{l}\text { Q1. For better home delivery service, the activities of } \\
\text { delivery staff and employees and my collaboration are } \\
\text { equally important }\end{array}$ & 4.01 & 0.907 & 0.651 \\
\hline & $\begin{array}{l}\text { Q2. I collaborate with the sender to make it easier for } \\
\text { him/her to send parcels when I am the receiver }\end{array}$ & 3.64 & 0.927 & 0.691 \\
\hline & $\begin{array}{l}\text { Q3. I collaborate with the receiver to make it easier for } \\
\text { him/her to receive parcels when I am the sender }\end{array}$ & 3.76 & 0.934 & 0.817 \\
\hline \multirow{6}{*}{$\begin{array}{l}\text { CPBs as } \\
\text { a Sender }\end{array}$} & $\begin{array}{l}\text { Q4. I search for information about the location of an office } \\
\text { or official retailer where I can leave the parcel }\end{array}$ & 3.23 & 1.21 & - \\
\hline & $\begin{array}{l}\text { Q5. I search for information about the sending services } \\
\text { such as the way to send the parcel }\end{array}$ & 3.61 & 0.958 & 0.665 \\
\hline & $\begin{array}{l}\text { Q6. I answer all service-related questions from the } \\
\text { employee }\end{array}$ & 3.93 & 0.917 & 0.81 \\
\hline & $\begin{array}{l}\text { Q7. I provide necessary information for the employee such } \\
\text { as specified delivery time }\end{array}$ & 3.49 & 1.00 & 0.565 \\
\hline & Q8. I am polite to the employee & 3.95 & 0.992 & 0.815 \\
\hline & $\begin{array}{l}\text { Q9. I perform all the tasks that are required to send the } \\
\text { parcel }\end{array}$ & 3.79 & 0.928 & 0.846 \\
\hline \multirow{6}{*}{$\begin{array}{l}\text { CPBs as } \\
\text { a Receiver }\end{array}$} & $\begin{array}{l}\text { Q10. I search for information about the location of an } \\
\text { office or official retailer where I can receive the parcel }\end{array}$ & 2.61 & 1.12 & - \\
\hline & $\begin{array}{l}\text { Q11. I search for information about the receiving services } \\
\text { such as the way to receive the parcel }\end{array}$ & 3.38 & 0.973 & 0.516 \\
\hline & $\begin{array}{l}\text { Q12. I answer all service-related questions from the } \\
\text { delivery staff }\end{array}$ & 3.97 & 911 & 0.771 \\
\hline & $\begin{array}{l}\text { Q13. I provide necessary information for the delivery staff } \\
\text { such as specified delivery time }\end{array}$ & 3.23 & 1.06 & 0.361 \\
\hline & Q14. I am polite to the delivery staff & 3.90 & 1.02 & 0.758 \\
\hline & $\begin{array}{l}\text { Q15. I perform all the tasks that are required to receive a } \\
\text { parcel }\end{array}$ & 3.71 & 0.926 & 0.756 \\
\hline \multirow{3}{*}{$\begin{array}{l}\text { SI (Feelings } \\
\text { of belonging } \\
\text { to society) }\end{array}$} & $\begin{array}{l}\text { Q16. I am actively participating in activities with people } \\
\text { around me }\end{array}$ & 2.72 & 1.05 & 0.766 \\
\hline & Q17. I can positively engage with people around me & 2.89 & 1.01 & 0.874 \\
\hline & Q18. I can mingle with people voluntarily & 2.86 & 0.991 & 0.765 \\
\hline
\end{tabular}




\begin{tabular}{|c|c|c|c|c|}
\hline \multirow{3}{*}{$\begin{array}{c}\text { SI } \\
\text { (Trust in } \\
\text { society) }\end{array}$} & Q19. I will never doubt people thoughtlessly & 3.07 & 0.959 & 0.633 \\
\hline & Q20. I believe others in general & 3.13 & 0.945 & 0.773 \\
\hline & Q21. There is a person who can be relied upon & 3.35 & 1.01 & 0.494 \\
\hline \multirow{3}{*}{$\begin{array}{l}\text { SI (Feelings } \\
\text { of } \\
\text { contribution) }\end{array}$} & Q22. I can behave voluntarily for the people around me & 3.14 & 0.897 & 0.732 \\
\hline & Q23. I can show sympathy for other people & 3.25 & 0.894 & 0.708 \\
\hline & Q24. I can help people voluntarily & 3.04 & 0.873 & 0.752 \\
\hline \multirow{3}{*}{$\begin{array}{c}\text { SI } \\
\text { (Self- } \\
\text { acceptance) }\end{array}$} & Q25. I like myself including my shortcomings & 3.09 & 1.07 & 0.714 \\
\hline & Q26. I cherish my present self & 3.46 & 0.972 & 0.702 \\
\hline & Q27. I have something to be proud of & 3.05 & 0.992 & 0.644 \\
\hline \multirow{3}{*}{$\begin{array}{l}\text { Perceived } \\
\text { Risk }\end{array}$} & Q28. The procedure for receiving the parcel is complicated & 2.33 & 0.937 & 0.799 \\
\hline & Q29. The procedure for sending the parcel is complicated & 2.55 & 0.94 & 0.678 \\
\hline & $\begin{array}{l}\text { Q30. I feel uneasy when being served by the employee who } \\
\text { have not seen much }\end{array}$ & 2.66 & 0.97 & 0.353 \\
\hline
\end{tabular}

\section{Appendix 2}

Social interest consists of four latent variables of "feelings of belonging to society", "trust in society", "feelings of contribution", and "self-acceptance" (Kosaka 2011). Confirmatory factor analysis was performed on this structure. As a result, CFI $=.951$, PCFI $=.720$, GFI $=.961$, AGFI $=.939$, and RMSEA $=.067$. Table A2 shows the normalization coefficients of each variable. For each question item, refer to the number in Table A2.

TABLE A2 STANDARDIZED COEFFICIENT

\begin{tabular}{|c|c|}
\hline Pass & $\begin{array}{c}\text { Standardized } \\
\text { Coefficient }\end{array}$ \\
\hline Feeling of belonging $\leftarrow$ Social Interest & $.794 * * *$ \\
\hline Trust in Society $\leftarrow$ Social Interest & $.801 * * *$ \\
\hline Feeling of contribution $\leftarrow$ Social Interest & $.931 * * *$ \\
\hline Self-Acceptance $\leftarrow$ Social Interest & $.753 * * *$ \\
\hline Q16 «Feeling of belonging & $.767 * * *$ \\
\hline Q17 —Feeling of belonging & $.871 * * *$ \\
\hline Q18 $\leftarrow$ Feeling of belonging & $.768 * * *$ \\
\hline Q19 —Trust in Society & $.635^{* * *}$ \\
\hline Q20 —Trust in Society & $.785 * * *$ \\
\hline Q21 —Trust in Society & $.479 * * *$ \\
\hline Q22 $\leftarrow$ Feeling of contribution & $.737 * * *$ \\
\hline Q23 $\leftarrow$ Feeling of contribution & $.696^{* * *}$ \\
\hline Q24 $\leftarrow$ Feeling of contribution & $.760 * * *$ \\
\hline Q25 —Self-Acceptance & $.718 * * *$ \\
\hline Q26 —Self-Acceptance & $.692 * * *$ \\
\hline Q27 —Self-Acceptance & $.649 * * *$ \\
\hline
\end{tabular}

